\title{
Oxytetracycline Toxicity and Its Effect on Phytoremediation by Sedum plumbizincicola and Medicago sativa in Metal-Contaminated Soil
}

Tingting Ma, ${ }^{\dagger, \ddagger, I L}$ Liqiang Zhou, ${ }^{\S, \text { II }}$ Li'ke Chen, ${ }^{\|} \mathrm{Zhu} \mathrm{Li}^{\dagger}{ }^{\dagger}$ Longhua Wu, ${ }^{*}$, Peter Christie, $^{\dagger}$ and Yongming Luo ${ }^{\dagger, \perp}$

\author{
${ }^{\dagger}$ Key Laboratory of Soil Environment and Pollution Remediation, Institute of Soil Science, Chinese Academy of Sciences, Nanjing \\ 210008, China \\ ${ }^{\ddagger}$ Institute of Hanjiang, Hubei University of Arts and Science, Xiangyang 441053, China \\ ${ }^{\S}$ Chongqing Solid Wastes Management Center, Chongqing 401147, China \\ "Shanghai Research Institute of Chemical Industry, Shanghai 200062, China \\ ${ }^{\perp}$ Key Laboratory of Coastal Zone Environmental Processes, Yantai Institute of Coastal Zone Research, Chinese Academy of Sciences, \\ Yantai 264003, China
}

ABSTRACT: Excessive use of antibiotics potentially threatens human health, agricultural production, and soil phytoremediation. This arouses concern over the potential adverse effects of a commonly used antibiotic, oxytetracycline (OTC), on plants used for soil remediation and possible stimulation of antibiotic resistance genes in soils. A greenhouse experiment was conducted to investigate different rates $\left(0,1,5\right.$, and $\left.25 \mathrm{mg} \mathrm{kg}^{-1}\right)$ and frequencies (one single high and daily low application) of OTC addition to soil on phytoremediation of a heavy metal contaminated soil by Sedum plumbizincicola and/or Medicago sativa (alfalfa). After 90 days both $\mathrm{Cd}$ and $\mathrm{Zn}$ were substantially removed by phytoextraction into S. plumbizincicola shoots especially at the high OTC $\left(25 \mathrm{mg} \mathrm{kg}^{-1}\right)$ treatment which also led to inhibition of antioxidative enzyme activities in both plant species. Soil microbial activity decreased significantly with the addition of OTC, and this was ameliorated by planting alfalfa and S. plumbizincicola together. OTC at $<5 \mathrm{mg} \mathrm{kg}^{-1}$ increased the biomass of both plant species, but the frequency of OTC addition had no effect on the rate of metal removal. Alfalfa exhibited greater detoxification ability and effectiveness in soil microbial activity promotion than S. plumbizincicola with intercropping. Phytoremediation by alfalfa and S. plumbizincicola in association can both promote the removal of heavy metals and also alleviate the toxic effects of pollutants on plants and soil microbes even at relatively high soil OTC concentrations.

KEYWORDS: phytoextraction, hyperaccumulator, oxytetracycline, biolog, enzyme activity, microbial activity

\section{INTRODUCTION}

Phytoremediation has been described as a valuable and promising approach of in situ soil remediation involving the utilization of solar energy, and its application has been investigated in dealing with organics and/or heavy metals in soils and waters. ${ }^{1-3}$ The high efficiency of hyperaccumulator plants in the extraction, sequestration, and/or detoxification of pollutants to remediate heavy metal polluted soils and the practical advantages in simultaneous agricultural production and soil remediation have made it an environmentally friendly, effective, and socially acceptable technology. ${ }^{4-7}$

Overuse and/or misuse of antibiotics in clinical and veterinary medicine, agriculture, aquaculture, and horticulture have led to large quantities of antibiotic residues in the environment, resulting in a worldwide threat to human health. ${ }^{8-10}$ Oxytetracycline (OTC) is one of the most extensively used and representative tetracycline antibiotics in intensively managed animal feeding operations, and it has been reported to occur at concentrations of up to $2.98 \mathrm{mg} \mathrm{kg}^{-1}$ in manures and $5.17 \mathrm{mg}$ $\mathrm{kg}^{-1}$ in soils of some livestock farms and organic vegetable farms in China. ${ }^{1-14}$ The land application of wastewater sludges, sewage, and livestock manures for the agricultural recycling of plant nutrients is the most common source of antibiotic inputs to agricultural soils, together with heavy metals, thus endangering soil biological systems by virtue of their biological toxicity, effects on the behavior of heavy metals or other pollutants, and their role as reservoirs for antibiotic resistance genes associated with human pathogens. ${ }^{9,13,15-20}$ However, the effects of antibiotic compounds on the growth of remediating plants and their phytoremediation efficiency with respect to soil heavy metals have not been reported and so far have received little attention, although OTC has been shown to damage some vegetable plants. $^{21}$

Uptake of antibiotics, especially tetracyclines, has been demonstrated to inhibit root elongation and the whole plant growth of rice, soybean, and other plant species to some extent. ${ }^{22-24}$ High rates of OTC $(0.2 \mathrm{mM})$ changed the color of Medicago sativa L. (alfalfa) leaves to light green or yellow. ${ }^{25}$ On the other hand, antibiotics may be directly harmful to soil

Received: May 11, 2016

Revised: September 15, 2016

Accepted: October 5, 2016

Published: October 5, 2016 
microorganisms including those that aid the phytoremediation process and in turn indirectly lower the efficiency of phytoremediation. $^{26}$ Alfalfa is a popular leguminous green plant and has been used for the remediation of many types of organic pollutants. ${ }^{27,28}$ Hyperaccumulator Sedum plumbizincicola has been screened for the in situ phytoremediation of soils contaminated with both $\mathrm{Cd}$ and $\mathrm{Zn}$ and has shown great potential in repeated phytoextraction in preliminary greenhouse and field experiments. ${ }^{29-31}$

To simulate the effects of OTC in sewage sludge and wastewater applications, different amounts and modes of OTC application treatments were employed to investigate the effects of OTC on phytoremediation efficiency by means of common antioxide enzyme determination in plants and OTC toxicity analysis to microorganisms in metal-contaminated soil on the growth of alfalfa and/or S. plumbizincicola in a pot experiment. This study may provide basic data on utilization of organic wastes in agriculture as sources of plant nutrients and as a remediation strategy for soils with combined contamination with antibiotics and other pollutants.

\section{MATERIALS AND METHODS}

Test Soil and Plants. The soil was collected from the top $20 \mathrm{~cm}$ (arable layer) of an area contaminated with cadmium (Cd) from wastewater irrigation at Zhangshi area, Shenyang, Liaoning province, northeast China. The soil is a typical Hapli-Udic Cambisol ${ }^{32}$ with $15.6 \%$ clay, $76.4 \%$ silt, $7.98 \%$ sand, and $2.92 \%$ organic matter. The soil $\mathrm{pH}$ is 6.66 , and the available nitrogen, phosphorus, and potassium concentrations are $1.29,2.26$, and $16.9 \mathrm{~g} \mathrm{~kg}^{-1}$, respectively. ${ }^{33}$ The soil collected was air-dried and passed through a $2 \mathrm{~mm}$ nylon sieve before use, and the background concentrations of $\mathrm{Cd}$, copper $(\mathrm{Cu})$, and zinc (Zn) were $3.73 \pm 0.11,80.6 \pm 0.9$, and $316 \pm 2 \mathrm{mg} \mathrm{kg}^{-1}$, respectively. The relative soil environmental quality standards (implementation standards of the second class soil environmental quality GB15618-1995 in China) were $0.3,100$, and $250 \mathrm{mg} \mathrm{kg}^{-1}$, respectively, to ensure agricultural production.

Alfalfa seeds were purchased from Jiangsu Provincial Academy of Agricultural Sciences (JAAS), and seeds of Sedum plumbizincicola, a Cd and $\mathrm{Zn}$ hyperaccumulator, ${ }^{27,28,30,31,34}$ were collected from a $\mathrm{Pb}-\mathrm{Zn}$ mine area in the suburbs of Hangzhou city, Zhejiang province, east China. Seeds of alfalfa were cultured using nonpolluted soil in a greenhouse for preincubation before seedlings of similar height with healthy well-developed root systems were selected for transplanting. Seeds of S. plumbizincicola were sown in trays with a matrix of vermiculite and a layer of perlite on the surface using Hoagland's nutrient solution ${ }^{31}$ before the seedlings had six true leaves and were then ready for use. Seedlings of both species were washed before transplanting to minimize effects of the soil or nutrient solution in which the seeds had germinated.

Chemicals and Instruments. Oxytetracycline (97.5\%) was obtained from Dr. Ehrenstorfer $\mathrm{GmbH}$, Augsburg, Germany. Dipotassium hydrogen phosphate $\left(\mathrm{K}_{2} \mathrm{HPO}_{4}\right)$, potassium chloride $(\mathrm{KCl})$, potassium hydroxide $(\mathrm{KOH})$, hydrogen peroxide $\left(\mathrm{H}_{2} \mathrm{O}_{2}\right)$, and glacial acetic acid $\left(\mathrm{CH}_{3} \mathrm{COOH}\right)$ were all analytical reagents purchased from the National Pharmaceutical Group Chemical Reagent Co. Ltd. (Shanghai, China). Disodium hydrogen phosphate $\left(\mathrm{Na}_{2} \mathrm{HPO}_{4}\right)$, omethoxyphenol, riboflavin, sodium hydroxide $(\mathrm{NaOH})$, ethylenediaminetetraacetic acid disodium salt (EDTA- $\left.\mathrm{Na}_{2}\right)$, sodium chloride $(\mathrm{NaCl})$, ethyl alcohol, and acetone were all analytical reagents purchased from Nanjing Chemical Reagent Co. Ltd. (Nanjing, China).

Assay kits A045-3 for total protein content assay, A001-1 for superoxide dismutase (SOD) activity assay, A084-1 for peroxidase (POD) activity assay, and A004 for catalase (CAT) activity assay were purchased from Nanjing Jiancheng Bioengineering Institute (Nanjing, China). Biolog Ecoplates were purchased from Biolog, Inc. (Hayward, U.S.A.).
Phytoremediation Experiment. The four single addition treatments, comprising OTC concentrations of $0,1,5$, and $25 \mathrm{mg} \mathrm{kg}^{-1}$ soil (dry weight, DW), and the low dosage daily input of $0.28 \mathrm{mg} \mathrm{OTC} \mathrm{kg}^{-1}$ soil (DW, in total $25.2 \mathrm{mg} \mathrm{OTC} \mathrm{kg}^{-1}$ soil) comprising the fifth treatment were set up for a cultivation period of 90 days. In each treatment a control (CK), S. plumbizincicola monoculture (S), alfalfa monoculture (A), and S. plumbizincicola intercropped with alfalfa $(\mathrm{S}+\mathrm{A})$ were set up in triplicate. The pot experiment was carried out in a greenhouse at the Institute of Soil Science, Chinese Academy of Sciences (ISSCAS), Nanjing. Plastic pots $(15 \mathrm{~cm}$ height $\times 10 \mathrm{~cm}$ diameter) each containing 1 $\mathrm{kg}$ of soil (oven dry basis) were arranged in a fully randomized design and rerandomized every week. Twenty milliliters of acetone stock solutions of different OTC concentrations were added and thoroughly mixed with the soil in each pot before seedlings were transplanted. In CK the same volume of acetone was added and mixed as a control treatment to avoid the influence of acetone on microbial activity and soil characteristics. However, aqueous OTC solution was sprayed onto the daily addition $0.28 \mathrm{mg} \mathrm{kg}^{-1}$ treatment every day during the incubation period. Scarification of the soil was carried out daily to minimize uneven distribution of the OTC applied. Four seedlings of alfalfa or eight seedlings of S. plumbizincicola were transplanted into each pot for the monoculture treatments, two seedlings of alfalfa and four seedlings of $S$. plumbizincicola in total for the intercropping treatments, and the CK pots remained unplanted and were placed in the same conditions as the experimental treatments. Analytical grade urea and $\mathrm{KH}_{2} \mathrm{PO}_{4}$ were applied during the experiment as fertilizers, and deionized water was added daily to maintain the soil water content at about $70 \%$ of soil water holding capacity (WHC).

Here, "S" denotes S. plumbizincicola monoculture; "A" is alfalfa monoculture, and "S+A" refers to S. plumbizincicola intercropped with alfalfa; "S" in S+A refers to S. plumbizincicola in S. plumbizincicola intercropped with alfalfa treatment; "A" in S+A refers to alfalfa in $S$. plumbizincicola intercropped with alfalfa treatment.

Sampling and Analysis. After 90 days both soil and plant samples were collected for the determination of the selected parameters. Half the harvested plant samples were immediately frozen in liquid nitrogen after washing with tap water three times, rinsing with deionized water, and wiping dry. Before determination of the $\mathrm{Cd}$ and $\mathrm{Zn}$ concentrations, root samples were washed in 10-20 mM EDTA-Na $\mathrm{Na}_{2}$ to remove heavy metals from the root surface. Frozen plant samples were ground to homogenates with ice-cold $0.05 \mathrm{~mol} \mathrm{~L}^{-1}$ potassium phosphate buffer $(\mathrm{PBS}, \mathrm{pH} 7.8)(w / v 1: 9)$ and centrifuged at $7104 g$ at $4{ }^{\circ} \mathrm{C}$ for $20 \mathrm{~min}$. The supernatant was used for further analysis of total protein content, superoxide dismutase (SOD) activity, peroxidase (POD) activity, and catalase (CAT) activity using the corresponding assay kits. The other half of the washed, rinsed, and wiped plant samples and $10 \mathrm{~g}$ of the soil samples from thoroughly mixed soil of each pot were freeze-dried in a Free Zone 2.5 Liter Freeze-Dry System (Labconco Corp., Kansas City, MO) for the determination of OTC and heavy metal concentrations (Cd and $\mathrm{Zn})$.

About $100 \mathrm{~g}$ of soil was collected and air-dried at room temperature and sieved through 20- and 100-mesh nylon sieves. Soil physical and chemical properties comprising water content, $\mathrm{pH}$ value, and organic matter content were determined. Total $\mathrm{Cd}$ and $\mathrm{Zn}$ concentrations in soil were determined after digestion with 4:1 $\mathrm{HCl}: \mathrm{HNO}_{3}(\mathrm{v} / \mathrm{v})$ according to McGrath and Cunliffe ${ }^{35}$ and in shoot subsamples after digestion with 3:2 $\mathrm{HCl}: \mathrm{HNO}_{3}(\mathrm{v} / \mathrm{v})$ according to $\mathrm{Li}$ et al. ${ }^{31}$ Copper and $\mathrm{Cd}$ concentrations were determined with a Varian 175 SpectrAA $220 Z$ spectrophotometer (Varian, Palo Alto, CA) equipped with a graphite Q4 furnace ${ }^{31}$ and $\mathrm{Zn}$ by flame atomic absorption spectrophotometry (Varian SpectrAA 220FS). The detection limits of the two spectrophotometers were $0.03 \mu \mathrm{g} \mathrm{L}^{-1}$ and $0.05 \mathrm{mg} \mathrm{L}^{-1}$ for $\mathrm{Cd}$ and $\mathrm{Zn}$, respectively. Blank controls and national standard reference materials GSV-2 were included in each batch of samples analyzed.

Five grams of fresh soil from each pot were sieved through a $250 \mu \mathrm{m}$ screen, added to $100 \mathrm{~mL}$ of distilled water in a $250 \mathrm{~mL}$ conical flask, and shaken at $200 \mathrm{rpm}$ for $20 \mathrm{~min}$ for the Biolog Eco test which was used to study the substrate utilization pattern of the soil microbial community. Tenfold serial dilutions were made, and a 100 -fold dilution of $150 \mu \mathrm{L}$ was used to inoculate the Biolog Ecoplates. Plates were incubated at 28 
Table 1. Concentrations of OTC Residues in Soils under the Different Treatments $\left(\mathrm{mg} \mathrm{kg}^{-1} \mathrm{DW}\right)^{a}$

$\begin{array}{ccccc}\text { OTC concentration added }\left(\mathrm{mg} \mathrm{kg}^{-1}\right) & \text { CK } & \text { S } & \text { A } & \text { S+A } \\ 1 & 0.10 \pm 0.03 \mathrm{~d} & 0.12 \pm 0.03 \mathrm{~d} & 0.11 \pm 0.03 \mathrm{~d} & 0.27 \pm 0.03 \mathrm{c} \\ 5 & 0.26 \pm 0.03 \mathrm{c} & 0.56 \pm 0.05 \mathrm{c} & 0.32 \pm 0.03 \mathrm{c} & 0.85 \pm 0.05 \mathrm{~b} \\ 25 & 1.25 \pm 0.05 \mathrm{a} & 2.17 \pm 0.07 \mathrm{a} & 2.08 \pm 0.10 \mathrm{a} & 1.32 \pm 0.03 \mathrm{a} \\ \text { daily } 0.28 & 0.83 \pm 0.09 \mathrm{~b} & 1.55 \pm 0.03 \mathrm{~b} & 1.39 \pm 0.10 \mathrm{~b} & 1.19 \pm 0.08 \mathrm{a}\end{array}$

${ }^{a} \mathrm{NB}$ : CK denotes the control treatment. The concentrations are mean values \pm standard error of the mean (SEM). Different letters denote significant difference at $p<0.05$ level within the same plant treatment.

Table 2. Residual OTC Concentrations in Plants under the Different Treatments $\left(\mathrm{mg} \mathrm{kg}^{-1} \mathrm{DW}\right)^{a}$

\begin{tabular}{cccccc} 
& & & \multicolumn{2}{c}{ S+A } \\
\cline { 3 - 5 } OTC concentration added $\left(\mathrm{mg} \mathrm{kg}^{-1}\right)$ & $\mathrm{S}$ & $\mathrm{A}$ & S. plumbizincicola & alfalfa \\
1 & $5.57 \pm 0.08 \mathrm{a}$ & $1.37 \pm 0.06 \mathrm{a}$ & $2.87 \pm 0.06 \mathrm{~b}$ & $1.42 \pm 0.05 \mathrm{a}$ \\
5 & $32.7 \pm 0.1 \mathrm{a}$ & $6.99 \pm 0.15 \mathrm{a}$ & $16.4 \pm 0.1 \mathrm{~b}$ & $7.13 \pm 0.04 \mathrm{a}$ \\
25 & $319 \pm 0 \mathrm{a}$ & $39.3 \pm 0.3 \mathrm{a}$ & $205 \pm 0 \mathrm{~b}$ & $59.1 \pm 0.1 \mathrm{~b}$ \\
daily 0.28 & $264 \pm 0 \mathrm{a}$ & $37.8 \pm 0.2 \mathrm{a}$ & $181 \pm 0 \mathrm{~b}$ & $20.1 \pm 0.1 \mathrm{~b}$
\end{tabular}

${ }^{a}$ NB: refer the abbreviations in Table 1 . The concentrations are mean values \pm SEM. Different letters denote significant difference of the same remediation plant species at $p<0.05$ level between groups within the same plant treatment.

${ }^{\circ} \mathrm{C}$, and color development was measured at $0,24,48,72,96,120,144$, and $168 \mathrm{~h}$ as absorbance difference at $590 \mathrm{~nm}$ using a $\mu$ Quant microplate spectrophotometer (BioTek, Winooski, VT), and the data were collected using the Gen 5 v 1.06 software package.

Mean values $(n=3)$ of average well color development (AWCD) were used as a measure of total microbial activity in different treatments over time and were compared at the $5 \%$ level of significance to evaluate their effects. $^{36}$

Shannon index and McIntosh index were also calculated.

$$
\operatorname{AWCD}=\sum_{i=1}^{n}\left(C_{i}-R\right) / n
$$

where $C_{i}$ is the color absorbance value of the reaction well, $R$ the color absorbance value of the control well, and $n$ the carbon source number, 31 .

Shannon diversity index:

$$
H=-\sum_{i}^{n} P_{i} \times \ln P_{i}
$$

where $P_{\mathrm{i}}$ is each reaction well subtracting the absorbance value of the control well and then dividing by the summed color absorbance value of 31 wells.

McIntosh index:

$$
U=\sqrt{\left(\sum_{i=1}^{n} p_{i}^{2}\right)}
$$

Data Analysis. All data were processed with Microsoft Excel 2013 and the SPSS v.18.0 software package. The data were analyzed for significant differences from the control treatment or between treatments using one-way analysis of variance.

\section{RESULTS}

OTC Concentrations in Soils and Plants. After 90 days of the pot experiment only $10.0,5.2$, and $5.0 \%$ of the OTC remained in the controls compared to the initial spiked concentrations of 1,5 , and $25 \mathrm{mg} \mathrm{kg}^{-1}$ (Table 1 ). The residual concentrations in the soil with the single large OTC application (25 mg OTC kg ${ }^{-1}$ soil) were higher than in that with the total equivalent daily addition ( $0.28 \mathrm{mg}$ OTC $\mathrm{kg}^{-1}$ soil per day). In addition, more OTC remained in the soil in treatments with plants $(\mathrm{S}, \mathrm{A}, \mathrm{S}+\mathrm{A})$ than the unplanted control $(\mathrm{CK})$ pots.

The plant OTC concentrations increased with increasing application rate of OTC to the soil irrespective of plant species or treatment (Table 2). Furthermore, plant OTC concentrations in treatments $\mathrm{S}, \mathrm{A}, \mathrm{S}$ in $\mathrm{S}+\mathrm{A}$, and $\mathrm{A}$ in $\mathrm{S}+\mathrm{A}$ receiving daily applications $\left(0.28 \mathrm{mg}\right.$ OTC $\mathrm{kg}^{-1}$ soil) were always lower than those that received the single application of $25 \mathrm{mg} \mathrm{OTC} \mathrm{kg}^{-1}$ soil, although these two treatments were designed to apply the same total amount of OTC within the 90-day period of the pot experiment (Table 2). Intercropping decreased OTC accumulation in S. plumbizincicola ( $\mathrm{S}$ in "S+A") compared with the monoculture treatments $(S)$. There was much higher accumulation of OTC in S. plumbizincicola than in alfalfa in soil at the same application rates of OTC. The OTC concentration in $S$.

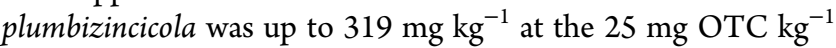
soil in S. plumbizincicola monoculture treatment $(\mathrm{S})$, and the corresponding value in alfalfa was only $39.3 \mathrm{mg} \mathrm{kg}^{-1}$ in the monoculture treatment (A).

Soil Heavy Metal Concentrations. The soil concentrations of $\mathrm{Cd}$ and $\mathrm{Zn}$ in the control pots showed no significant difference at the end of the experiment. However, compared with the controls there were significant decreases in soil $\mathrm{Cd}$ in the experimental treatments with plants $(\mathrm{S}, \mathrm{A}$, and $\mathrm{S}+\mathrm{A})$ at all rates of OTC addition (Figure 1). However, there were no differences in soil $\mathrm{Cd}$ concentration in the alfalfa monoculture treatment (A) with different rates of OTC addition except for the daily adding treatment, but the Cd concentrations in the soil planted with $S$. plumbizincicola ( $\mathrm{S}$ or $\mathrm{S}+\mathrm{A}$ ) showed a decreasing trend with an increasing rate of OTC addition. There was a significant difference in soil $\mathrm{Cd}$ concentration between the soils with daily OTC addition $\left(0.28 \mathrm{mg} \mathrm{kg}^{-1}\right)$ and the single high rate of addition $\left(25 \mathrm{mg} \mathrm{kg}^{-1}\right)$. The decrease in Cd in daily OTC addition $(0.28$ $\mathrm{mg} \mathrm{kg}^{-1}$ ) was similar to the control. Soil $\mathrm{Zn}$ decreased in the treatments with plants $(\mathrm{S}, \mathrm{A}$, and $\mathrm{S}+\mathrm{A})$, especially in the treatment with intercropping plants compared with the control. However, no change in soil $\mathrm{Zn}$ was found in the same planting treatment (Figure 1) but with different rates of addition of OTC, although an enhancement effect of high concentration of OTC on $\mathrm{Zn}$ uptake by S. plumbizincicola was also found (Figure 2). Cd uptake in S. plumbizincicola also increased in both daily OTC addition $\left(0.28 \mathrm{mg} \mathrm{kg}^{-1}\right)$ and the single high rate of addition (25 $\mathrm{mg} \mathrm{kg}^{-1}$ ) treatment more than others (Figure 2).

Plant Biomass and Heavy Metal Concentrations. The addition of OTC significantly increased the biomass of $S$. plumbizincicola (S or S in S+A) (Table 3). The trend in alfalfa (A 

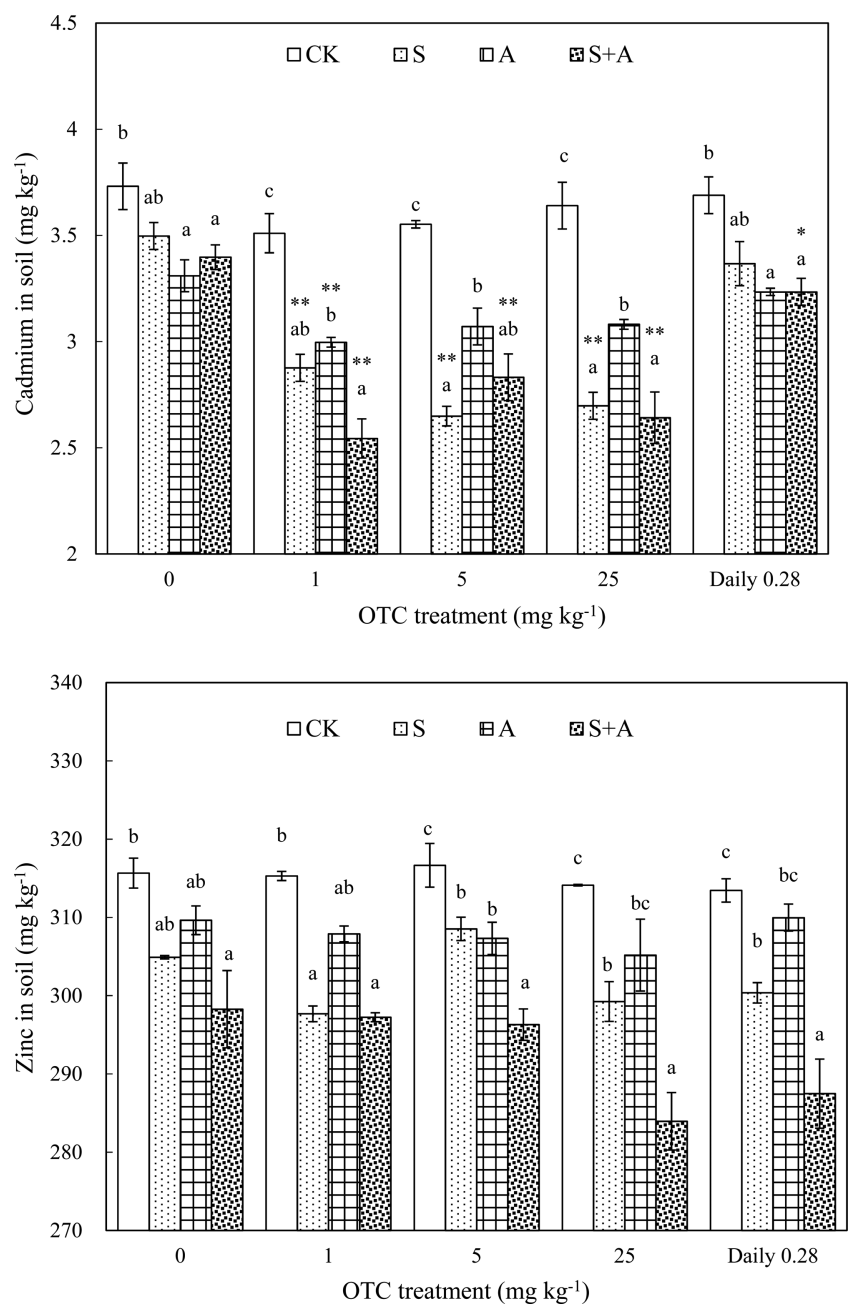

Figure 1. Soil cadmium and zinc concentrations in the different treatments. Each value is the mean of three replicates \pm standard error of the mean (SEM). "*” in columns denotes significant difference at $p<$ 0.05 level between treatments; “**” in columns denotes significant difference at $p<0.01$ level between treatments; different letters in columns denote significant difference at $p<0.05$ level between groups within the same treatment.

or A in S+A) was similar to that of S. plumbizincicola (S), but the concentration that gave the highest promotion of biomass was 1 $\mathrm{mg} \mathrm{kg}^{-1}$, lower than that of S. plumbizincicola (S) (Table 3).

S. plumbizincicola showed considerable ability to accumulate soil Cd and Zn compared with alfalfa (Figure 2). The ability of $S$. plumbizincicola to accumulate $\mathrm{Cd}$ was enhanced by the addition of OTC, especially at the high rate of $25 \mathrm{mg} \mathrm{kg}^{-1}$ and the daily OTC addition $\left(0.28 \mathrm{mg} \mathrm{kg}^{-1}\right)$ treatment. At high concentrations $\left(25 \mathrm{mg} \mathrm{kg}^{-1}\right)$ of OTC, increases in $\mathrm{Zn}$ accumulation were also observed in S. plumbizincicola, but the low addition rates ( 1 and 5 $\mathrm{mg} \mathrm{kg}{ }^{-1}$ ) significantly decreased $\mathrm{Zn}$ concentrations in $S$. plumbizincicola in monoculture as compared to plants growing in soil without OTC application (Figure 2). No significant difference in metal uptake was found between daily OTC application of $0.28 \mathrm{mg} \mathrm{kg}^{-1}$ and a single application of $25 \mathrm{mg}$ $\mathrm{kg}^{-1}$.

Total Protein Content and Activity of POD, SOD, and CAT in Plants. Effects of OTC on the biochemical indices, namely total protein content, SOD, POD, and CAT activity in shoots of $S$. plumbizincicola after 90 days, were measured (Figure 3). Total protein content increased slightly in S. plumbizincicola
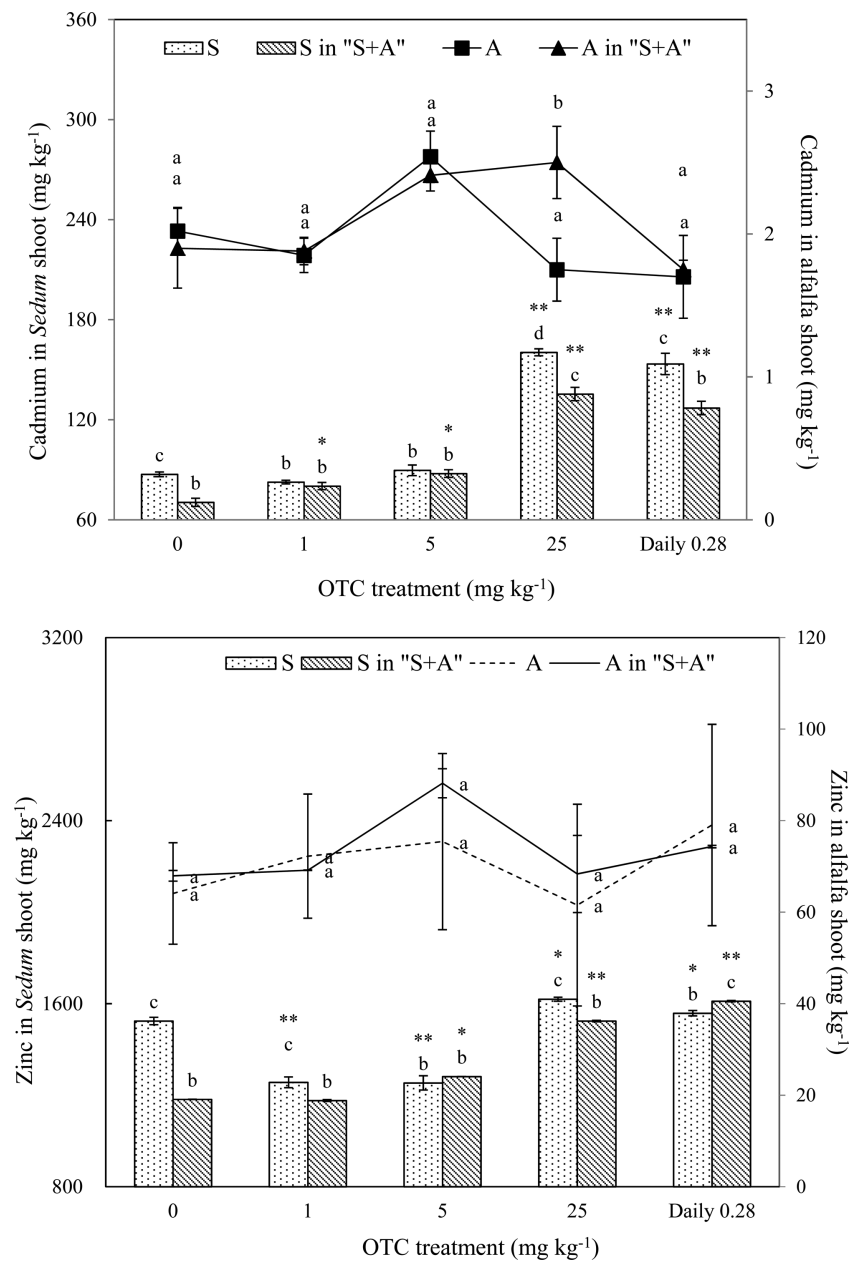

Figure 2. Concentrations of cadmium and zinc in plant shoots of the different treatments. Each value is the mean of three replicates \pm SEM. Other annotations as in Figure 1.

of $\mathrm{S}$ and $\mathrm{S}+\mathrm{A}$ at $1 \mathrm{mg} \mathrm{kg}-1$ OTC addition compared with treatments without OTC, but decreased subsequently at the OTC addition rates of 5 and $25 \mathrm{mg} \mathrm{kg}^{-1}$. The activity of SOD in our study was promoted in intercropping S. plumbizincicola but reduced in monoculture S. plumbizincicola (Figure 3), and that of CAT increased with increasing OTC concentration. The activity of POD was inhibited compared with treatments without OTC especially in S. plumbizincicola monoculture (S). Monoculture $S$. plumbizincicola $(S)$ in the daily addition treatment $\left(0.28 \mathrm{mg} \mathrm{kg}^{-1}\right.$ daily) showed less activity and less variation in SOD, POD, and CAT than the single high application $\left(25 \mathrm{mg} \mathrm{kg}^{-1}\right) . S$. plumbizincicola in the intercropping treatment ( $\mathrm{S}$ in $\mathrm{S}+\mathrm{A})$ had less total protein content but higher antioxidant enzyme activity than the monoculture $(S)$.

The corresponding results for alfalfa can be seen in Figure 4. There was no significant change in total protein content in the different OTC applications, except intercropping alfalfa in the 5 $\mathrm{mg} \mathrm{kg}^{-1}$ OTC treatment. However, the activities of SOD, POD, and CAT generally increased with increasing OTC concentration. A decline in enzyme activity under daily addition of OTC was found as compared with the single high application. Compared with monoculture alfalfa (A), the alfalfa in the intercropping treatment ( $\mathrm{A}$ in $\mathrm{S}+\mathrm{A}$ ) tended to show slightly higher activities of SOD, POD, and CAT (Figure 4). 
Table 3. Shoot Biomass of S. plumbizincicola and Alfalfa in the Different Treatments $\left(\mathrm{g} \mathrm{DW} \mathrm{pot}^{-1}\right)^{a}$

\begin{tabular}{|c|c|c|c|c|}
\hline \multirow[b]{2}{*}{ OTC concentration added $\left(\mathrm{mg} \mathrm{kg}^{-1}\right)$} & \multirow[b]{2}{*}{$S$} & \multirow[b]{2}{*}{ A } & \multicolumn{2}{|c|}{$\mathrm{S}+\mathrm{A}$} \\
\hline & & & S. plumbizincicola & alfalfa \\
\hline 0 & $3.70 \pm 0.20 \mathrm{a}$ & $30.3 \pm 0.5 \mathrm{a}$ & $3.99 \pm 0.36 \mathrm{a}$ & $15.3 \pm 0.5 \mathrm{a}$ \\
\hline 1 & $4.53 \pm 0.20 \mathrm{~b}$ & $34.5 \pm 0.5 b$ & $4.37 \pm 0.33 \mathrm{~b}$ & $17.3 \pm 0.3 b$ \\
\hline 5 & $5.02 \pm 0.27 \mathrm{c}$ & $30.9 \pm 0.5 \mathrm{a}$ & $4.64 \pm 0.44 \mathrm{~b}$ & $12.3 \pm 0.2 \mathrm{c}$ \\
\hline 25 & $4.37 \pm 0.18 \mathrm{~b}$ & $29.0 \pm 0.4 \mathrm{a}$ & $3.87 \pm 0.41 \mathrm{a}$ & $12.8 \pm 0.2 \mathrm{c}$ \\
\hline daily 0.28 & $5.23 \pm 0.24 c$ & $31.9 \pm 0.3 \mathrm{a}$ & $6.37 \pm 0.23 c$ & $10.0 \pm 0.3 \mathrm{~d}$ \\
\hline
\end{tabular}

${ }^{a}$ NB: Refer to the abbreviations in Table 1 . The shoot biomass values are mean values \pm SEM. Different letters denote significant difference of the same remediation plant species at $p<0.05$ level between groups within the same plant treatment.
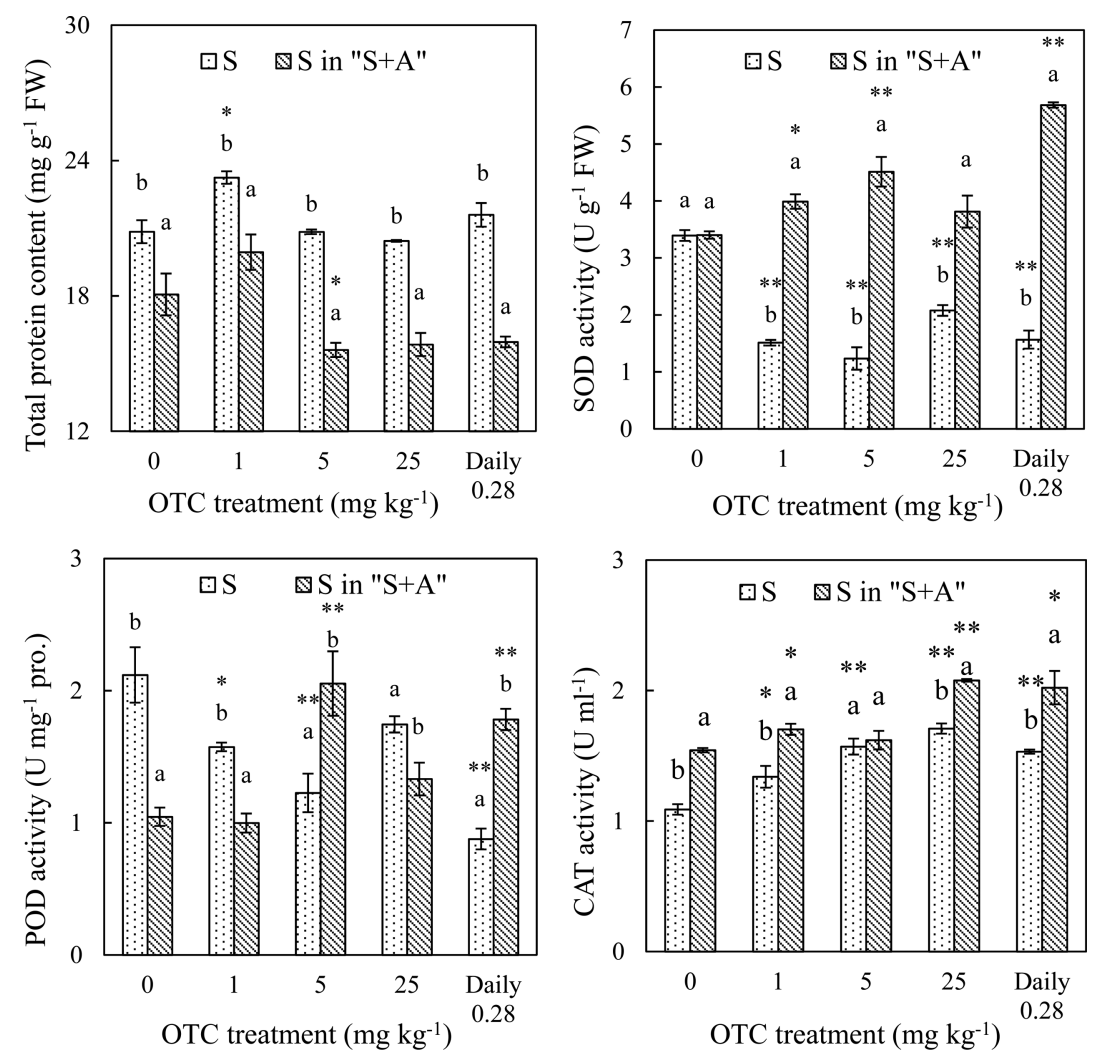

Figure 3. Effects of OTC on total protein content, SOD, POD, and CAT activity of Sedum plumbizincicola. Each value is the mean of three replicates \pm SEM. Other annotations as in Figure 1.

Functional Diversity of Soil Microorganisms. According to Figure 5, the AWCD values of soils increased with increasing culture period in all soils irrespective of OTC application or planting treatment. However, the control soil without OTC had the highest AWCD values during the culture period, followed by soil with $5 \mathrm{mg} \mathrm{kg}^{-1}$, and then the soil with 1 and $25 \mathrm{mg} \mathrm{kg}^{-1}$. Moreover, AWCD values in soil with daily $0.28 \mathrm{mg} \mathrm{kg}^{-1}$ OTC addition were significantly higher than the single $25 \mathrm{mg} \mathrm{kg}^{-1}$ addition. However, the above divergence effects of different OTC concentrations or the addition frequency on soil microorganisms decreased when the soil was planted with $S$. plumbizincicola and/or alfalfa. Especially in alfalfa monoculture and intercropped with S. plumbizincicola, the AWCD values were similar at all OTC application rates, and this trend occurred throughout the culture period.

Soil with different OTC addition showed different levels of inhibition of microbial activity (Figure 6). The Shannon and McIntosh indices in the soil with 1 and $25 \mathrm{mg} \mathrm{kg}^{-1}$ OTC addition in the control were significantly lower than that in the control soil without OTC (Figure 6). However, the daily addition treatments had higher diversity indices than the single application, illustrating the higher buffering effect of soil microorganisms to pollution at low concentrations. In monoculture S. plumbizincicola $(S)$ the diversity indices of different OTC additions to soil were no higher than that of the control soil. The Shannon index of monoculture alfalfa $(\mathrm{A})$ and the intercropping group (A in $\mathrm{S}$ $+A)$ showed no significant difference and some variation in McIntosh index but less severe than that of the control and monoculture S. plumbizincicola (S) soil.

\section{DISCUSSION}

OTC Concentrations in Soil and Plants. The substantially higher residual concentrations of OTC in the soil with the single large OTC application ( $25 \mathrm{mg}$ OTC kg${ }^{-1}$ soil) than the total equivalent daily addition ( $0.28 \mathrm{mg}$ OTC $\mathrm{kg}^{-1}$ soil per day) indicates that the gradual addition of OTC has shared in the contamination pressure with daily degradation. In addition, the results show that more OTC remained in the soil in treatments with plants $(\mathrm{S}, \mathrm{A}, \mathrm{S}+\mathrm{A})$ than the unplanted control pots, perhaps due to the likelihood that planting of S. plumbizincicola and/or 

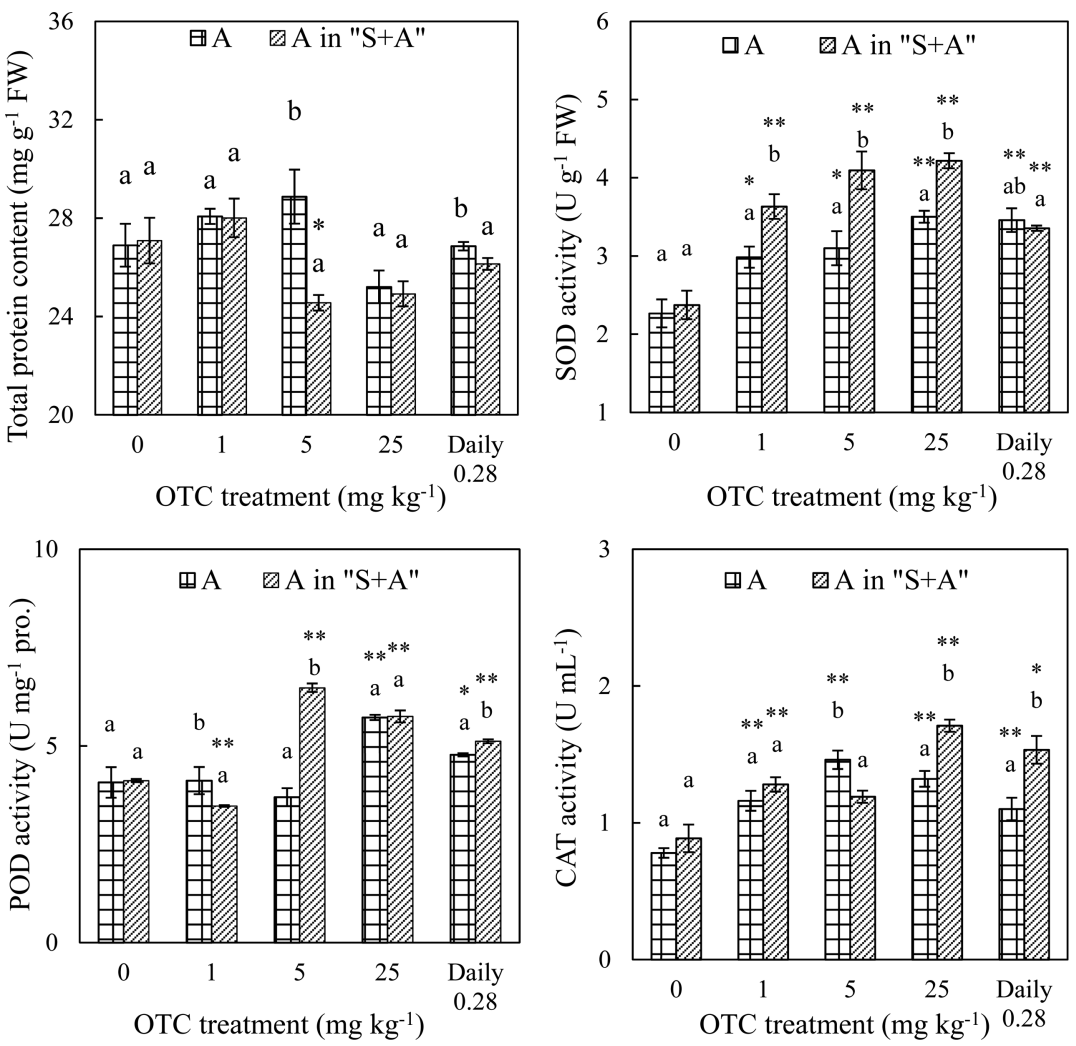

Figure 4. Effects of OTC on total protein content, SOD, POD, and CAT activity of alfalfa. Each value is the mean of three replicates \pm SEM. Other annotations as in Figure 1.

alfalfa $(\mathrm{S}, \mathrm{A}$, and $\mathrm{S}+\mathrm{A})$ would have reinforced the water holding capacity (WHC) of both the surface and the deeper soil in the pots, thus delaying the degradation of OTC compounds in the soil. However, it has been reported that sunlight and temperature show a statistically significant positive correlation with the degradation of OTC, ${ }^{37}$ so that the planting of S. plumbizincicola and/or alfalfa $(S, A$, and $S+A)$ might have protected OTC in soil from sunlight and protected the soil with OTC from increasing temperatures from the sunlight, and finally blocking the degradation of OTC in the soil.

Lower OTC concentrations in treatments $S, A, S$ in $S+A$, and A

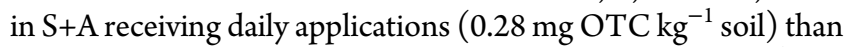
those receiving the single application of $25 \mathrm{mg} \mathrm{OTC} \mathrm{kg}^{-1}$ soil indicates that a single high-dose addition of OTC can enhance plant accumulation of OTC compared to long-term low dose application. Studies have confirmed that intercropping can change soil biochemical properties as compared to monocultures, ${ }^{38}$ and the present study supports this (Figure 4-6). S. plumbizincicola and alfalfa are shallow- and deep-rooting species, respectively, $^{28}$ and their different root distributions in the intercropping treatment might change soil water diffusion and thus the transfer of OTC to the plant roots with water. However, the mechanisms are speculative at present and require further investigation.

Interestingly, there was much higher accumulation of OTC in S. plumbizincicola than in alfalfa in soil at the same application rates of OTC. Much higher OTC accumulation by $S$. plumbizincicola than by other plant species was also found by $\mathrm{Hu}$ et al. ${ }^{11}$ In phytoremediation the ready OTC accumulation by $S$. plumbizincicola will influence the remediation efficiency of $S$. plumbizincicola by imposing toxicity on plant growth and metal uptake when the hyperaccumulator grows in soil polluted with metals and OTC together. The addition of OTC did not inhibit the growth of the remediation plants, S. plumbizincicola particularly, but also markedly increased the S. plumbizincicola plant biomass under most of the higher dosages (Table 3). Moreover, the present study has demonstrated the novel possibility of employing the hyperaccumulator S. plumbizincicola in the remediation of OTC polluted soil especially under the cooccurrence of heavy metals.

Soil Heavy Metal Concentrations. The soil concentrations of $\mathrm{Cd}$ and $\mathrm{Zn}$ in the control showed no significant differences at the end of the experiment, indicating that both plant species tested have the ability to remove $\mathrm{Cd}$ from the soil. $\mathrm{Cd}$ concentrations in the soils planted with S. plumbizincicola ( $\mathrm{S}$ or $\mathrm{S}+\mathrm{A}$ ) showed a decreasing trend with increasing rate of OTC addition, suggesting that OTC tended to increase the $\mathrm{Cd}$ remediation efficiency of $S$. plumbizincicola but not of alfalfa. This is supported by the much higher $\mathrm{Cd}$ concentrations in the shoots of S. plumbizincicola under the high rate of OTC addition to the soil (Figure 2). The absence of change in soil $\mathrm{Zn}$ found in the same planting treatment may be related to the higher background $\mathrm{Zn}$ concentrations leading to no significant residual variation in the soils at the end of the experiment. As the assays indicate, desorption of heavy metal ions such as $\mathrm{Cd}$ occurs under the competitive adsorption effect of OTC in soils, ${ }^{39,40}$ so OTC may have a positive effect on the activation of soil heavy metals and this may result in higher metal removal efficiency of phytoremediation. The appearance of OTC markedly enhanced the biomass of S. plumbizincicola (Table 3) but also benefited the removing of typical heavy metals such as $\mathrm{Cd}$ by increasing the concentration of $\mathrm{Cd}$ in the shoots.

Plant Biomass and Heavy Metal Concentrations. The promotion of $S$. plumbizincicola biomass by OTC especially at 5 

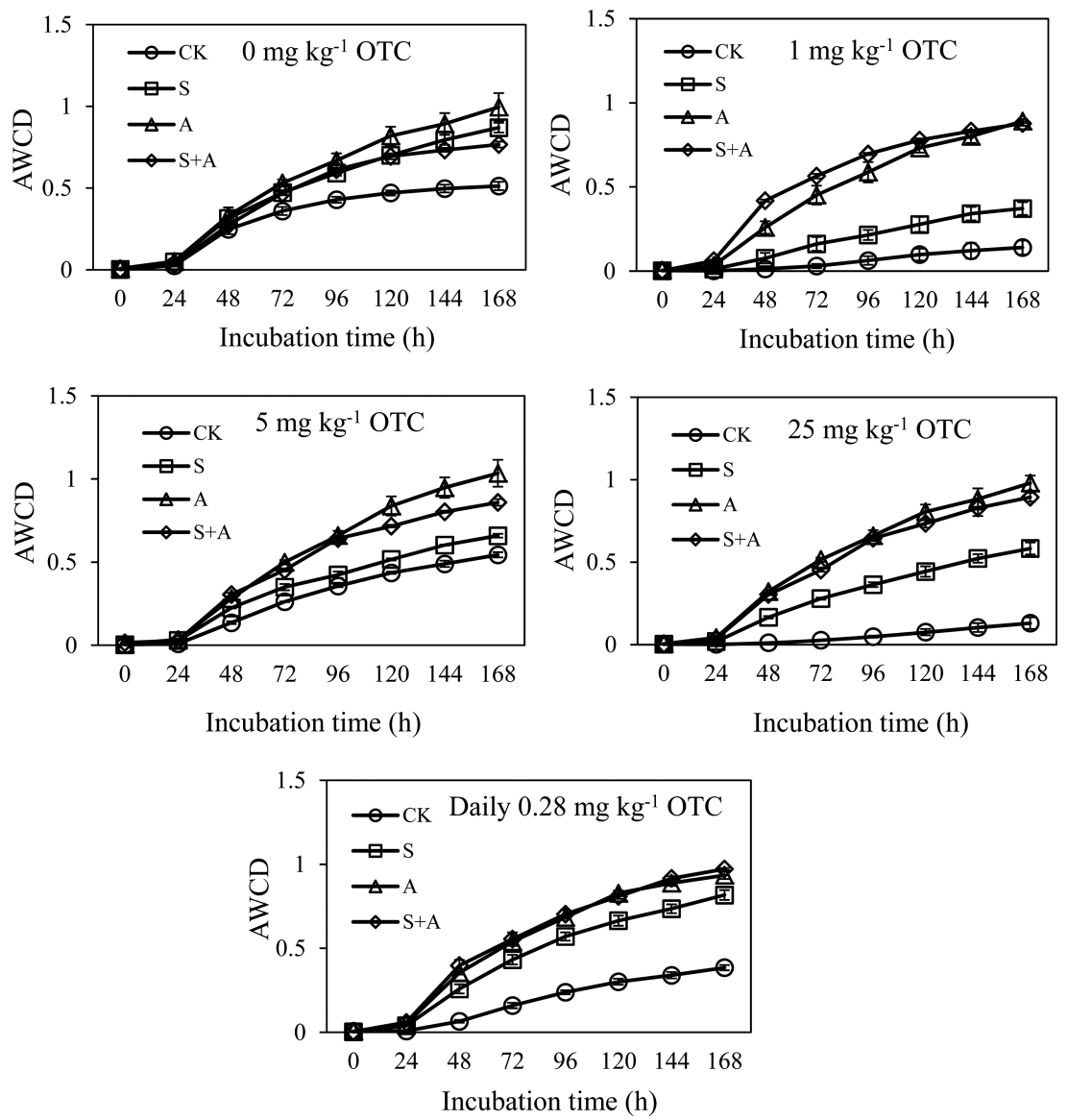

Figure 5. Average well color development (AWCD) values of soil under the different treatments after 90 days. Each value is the mean of three replicates \pm SEM. Other annotations as in Figure 1 .

$\mathrm{mg} \mathrm{kg}^{-1}$ and with daily addition of $0.28 \mathrm{mg} \mathrm{kg}^{-1}$ is considered to be in accordance with former studies showing that OTC can enhance $S$. plumbizincicola growth at lower concentrations but give inhibition at higher concentrations. ${ }^{41}$ The concentration that gave the highest promotion in alfalfa (A or A in S+A) was 1 $\mathrm{mg} \mathrm{kg}^{-1}$, lower than that of S. plumbizincicola (S) and indicating a higher sensitivity of alfalfa than $S$. plumbizincicola. If the amount of metal entering the plant from the soil does not change, the increase in plant biomass can decrease plant metal concentrations by a dilution effect, which explains the shoot $\mathrm{Zn}$ decrease at the low rates of OTC addition as the biomass increases (Figure 2). However, this explanation cannot fit the situation of high rates of OTC addition because the shoot biomass and plant metal ( $\mathrm{Cd}$ and $\mathrm{Zn}$ ) concentrations increased simultaneously at the high OTC application rate $\left(25 \mathrm{mg} \mathrm{kg}^{-1}\right.$ or with daily application of $0.28 \mathrm{mg} \mathrm{kg}^{-1}$ ). A previous study shows that high concentrations of OTC enhanced metal desorption from soil particles, ${ }^{40}$ and this might increase plant metal uptake from the soil. In addition, OTC can act as a form of organic matter, and the formation of organic-metal complexes might enhance metal transfer from soil to roots and/or from roots to shoots. ${ }^{42}$ The actual mechanism by which OTC promotes metal uptake by $S$. plumbizincicola still requires further confirmation, but the accumulation of heavy metals in S. plumbizincicola is more closely related to the total amount of OTC added rather than the frequency of application.

Low OTC concentrations $\left(<5 \mathrm{mg} \mathrm{kg}^{-1}\right)$ resulted in an increase in the biomass of both plant species, and the high OTC $(25 \mathrm{mg}$ $\mathrm{kg}^{-1}$ ) concentration significantly increased the shoot $\mathrm{Cd}$ and $\mathrm{Zn}$ concentrations of S. plumbizincicola and thus the efficiency of phytoremediation. Daily OTC application increased the shoot biomass as compared with a single large application, and the accumulation of heavy metals in S. plumbizincicola was lower with increased frequency of application.

Total Protein Content and Activity of POD, SOD, and CAT in Plants. Antioxidant status is of great importance in plant tolerance to stress from environmental pollutants which leads to increases in oxygen free radical levels and disturbs the antioxidative balance in organisms. ${ }^{43}$ The activity of SOD was inhibited compared with treatments without OTC in $S$. plumbizincicola monoculture $(\mathrm{S})$, which might be due to the consumption of SOD by the stimulated reactive $\mathrm{O}_{2}$ species (ROS) in different plant species constituting the first line of defense against excess ROS under stress conditions. ${ }^{44}$ Peroxidase (POD) and CAT play the role of splitting hydrogen peroxide into water and oxygen in plants. ${ }^{45,46}$ Thus, the long-term OTC treatment at low concentrations has made $S$. plumbizincicola expend antioxidant enzymes to alleviate the toxic effects caused by OTC every day as compared to the single high application.

The generally increased activities of SOD, POD, and CAT with increasing OTC concentration suggest a higher sensitivity of alfalfa to OTC contamination. A decline in enzyme activity of alfalfa under daily addition of OTC was found as compared with the single high application, suggesting that daily contamination consumed antioxidant enzymes day-by-day and led to higher environmental risk to the plants in a similar fashion to $S$. plumbizincicola. Total protein content under $5 \mathrm{mg} \mathrm{kg}^{-1} \mathrm{OTC}$ and POD in treatments except $\mathrm{CK}$ in alfalfa in the intercropping treatment ( $\mathrm{A}$ in $\mathrm{S}+\mathrm{A}$ ) demonstrate the general stress of 

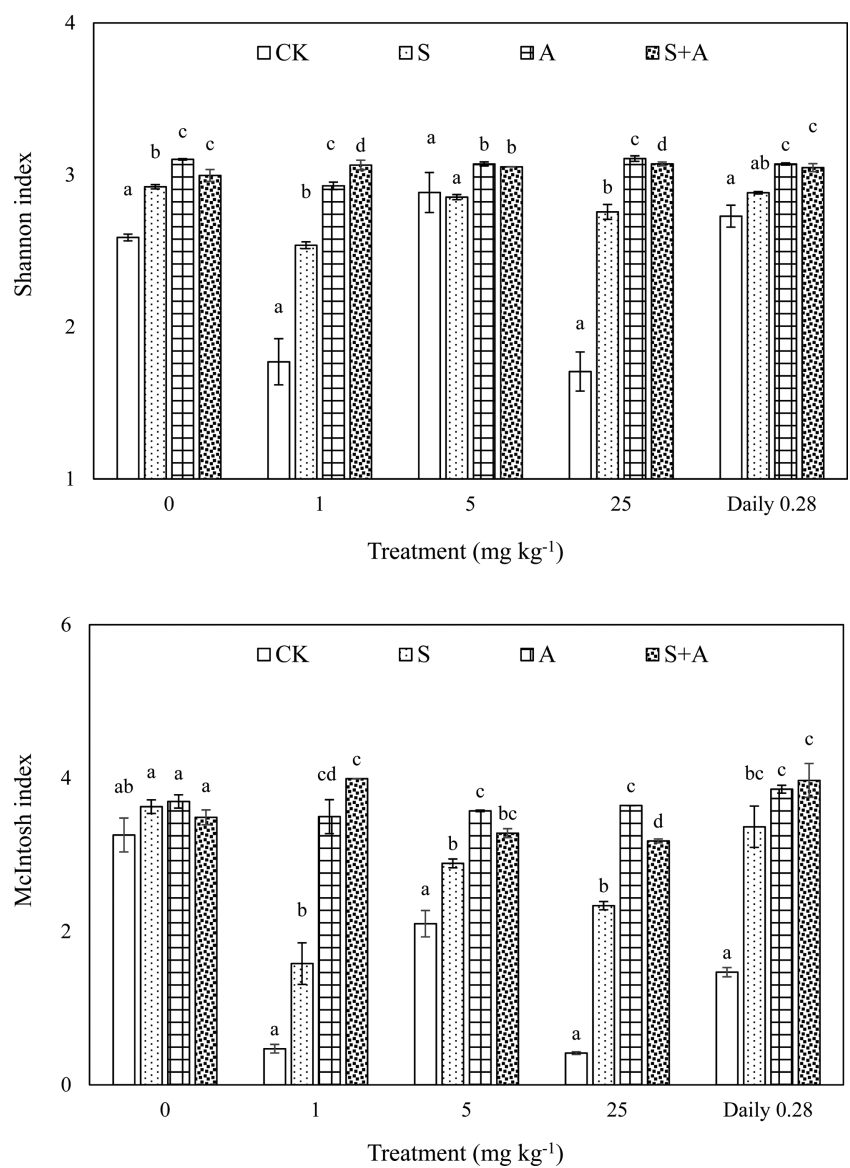

Figure 6. Effect of OTC on soil microbial diversity. Each value is the mean of three replicates \pm SEM. Other annotations as in Figure 1 .

intercropping, and pollutants have prepared alfalfa to start the defense mechanisms with which tolerant plant species mostly protect themselves including intensified antioxidant enzyme activity $^{47}$ in advance. Disturbance of antioxidation and detoxification systems might result in an inhibition of enzymes for toxicologically relevant responses induced by ROS. ${ }^{48}$ In view of the higher sensitivity of alfalfa to OTC contamination, the antioxidant detoxification system may be activated even at low concentrations, ${ }^{49}$ so its tolerance to long-term and low-level contamination is supposed to be higher than that of $S$. plumbizincicola.

Functional Diversity of Soil Microorganisms. The AWCD values suggest that low and high OTC contents decreased the activities of soil microorganisms, but the effects were weakened in soil with an intermediate amount of $5 \mathrm{mg} \mathrm{kg}^{-1}$ OTC. Moreover, higher AWCD values in soil with daily $0.28 \mathrm{mg}$ $\mathrm{kg}^{-1}$ OTC addition than the single $25 \mathrm{mg} \mathrm{kg}^{-1}$ addition suggests the toxicity of the single high application to soil microorganisms was higher than daily application. Thus, the resistance of soil microorganisms to OTC may have been enhanced by the growing plants, and the effect of alfalfa was stronger than that of S. plumbizincicola.

The daily addition treatments had higher diversity indices (Shannon and McIntosh indices) than the single application, illustrating the higher buffering effect of soil microorganisms to contamination at low concentrations. The soil diversity indices of different OTC additions in monoculture S. plumbizincicola (S) treatments suggest that the presence of $S$. plumbizincicola alleviated the stress of OTC to soil microorganisms. The
Shannon index of monoculture alfalfa (A) and intercropping group (A in S+A) indicate the important effect of the alfalfa rhizosphere on the diversity of soil microorganisms and on the alleviation of the toxic effects to soil microorganisms.

In conclusion, soil microbial activity was significantly changed by the addition of OTC and may be ameliorated by planting alfalfa or S. plumbizincicola, and the alfalfa was more effective in this respect than S. plumbizincicola.

\section{AUTHOR INFORMATION}

\section{Corresponding Author}

*Tel.: +86 25 86881128. Fax: +86 2586881126 . E-mail address: lhwu@issas.ac.cn.

\section{Author Contributions}

II These authors contributed equally.

\section{Funding}

This research was supported by the National Natural Science Foundation of China (41401581 and 41271326).

Notes

The authors declare no competing financial interest.

\section{REFERENCES}

(1) Susarla, S.; Medina, V. F.; McCutcheon, S. C. Phytoremediation: An ecological solution to organic chemical contamination. Ecol. Eng. 2002, 18, 647-658.

(2) Singh, O.; Jain, R. Phytoremediation of toxic aromatic pollutants from soil. Appl. Microbiol. Biotechnol. 2003, 63, 128-135.

(3) Pilon-Smits, E. Phytoremediation. Annu. Rev. Plant Biol. 2005, 56, $15-39$.

(4) Alkorta, I.; Garbisu, C. Phytoremediation of organic contaminants in soils. Bioresour. Technol. 2001, 79, 273-276.

(5) Audet, P.; Charest, C. Heavy metal phytoremediation from a metaanalytical perspective. Environ. Pollut. 2007, 147, 231-237.

(6) Cheng, M.; Wu, L.; Huang, Y.; Luo, Y.; Christie, P. Total concentrations of heavy metals and occurrence of antibiotics in sewage sludges from cities throughout China. J. Soils Sediments 2014, 14, 11231135.

(7) Hettick, B. E.; Cañas-Carrell, J. E.; French, A. D.; Klein, D. M. Arsenic: A review of the element's toxicity, plant interactions, and potential methods of remediation. J. Agric. Food Chem. 2015, 63, 70977107.

(8) Rizzo, L.; Manaia, C.; Merlin, C.; Schwartz, T.; Dagot, C.; Ploy, M. C.; Michael, I.; Fatta-Kassinos, D. Urban wastewater treatment plants as hotspots for antibiotic resistant bacteria and genes spread into the environment: a review. Sci. Total Environ. 2013, 447, 345-360.

(9) Ma, J.; Zhai, G. Antibiotic contamination: A global environment issue. J. Biorem. Biodegrad. 2014, 5, e157.

(10) Bailey, C.; Spielmeyer, A.; Frings, R. M.; Hamscher, G.; Schüttrumpf, H. From agricultural fields to surface water systems: The overland transport of veterinary antibiotics. J. Soils Sediments 2015, $15,1630-1634$

(11) Hu, X.; Zhou, Q.; Luo, Y. Occurrence and source analysis of typical veterinary antibiotics in manure, soil, vegetables, and groundwater from organic vegetable bases, northern China. Environ. Pollut. 2010, 158, 2992-2998.

(12) Li, Y. W.; Wu, X. L.; Mo, C. H.; Tai, Y. P.; Huang, X. P.; Xiang, L. Investigation of sulfonamide, tetracycline, and quinolone antibiotics in vegetable farmland soil in the Pearl River Delta area, Southern China. J. Agric. Food Chem. 2011, 59, 7268-7276.

(13) Kang, D. H.; Gupta, S.; Rosen, C.; Fritz, V.; Singh, A.; Chander, Y.; Murray, H.; Rohwer, C. Antibiotic uptake by vegetable crops from manure-applied soils. J. Agric. Food Chem. 2013, 61, 9992-10001.

(14) Shen, D. S.; Tao, X. Q.; Shentu, J. L.; Wang, M. Z. Residues of veterinary antibiotics in pig feeds and manures in Zhejiang Province. Adv. Mater. Res. 2014, 1010-1012, 301-304. 
(15) Boxall, A. B. A.; Johnson, P.; Smith, E. J.; Sinclair, C. J.; Stutt, E.; Levy, L. S. Uptake of veterinary medicines from soils into plants. J. Agric. Food Chem. 2006, 54, 2288-2297.

(16) Gulkowska, A.; Leung, H. W.; So, M. K.; Taniyasu, S.; Yamashita, N.; Yeung, L. W. Y.; Richardson, B. J.; Lei, A. P.; Giesy, J. P.; Lam, P. K. S. Removal of antibiotics from wastewater by sewage treatment facilities in Hong Kong and Shenzhen, China. Water Res. 2008, 42, 395-403.

(17) Pan, X.; Chen, L.-k.; Bu, Y.-q.; Zhang, H.-b.; Wu, L.-h.; Teng, Y.; Luo, Y.-m. Effects of livestock manure on distribution of heavy metals and antibiotics in soil profiles of typical vegetable fields and orchards. J. Ecol. Rural Environ. (in Chinese) 2012, 28, 518-525.

(18) Gao, M.; Song, W.; Zhou, Q.; Ma, X.; Chen, X. Interactive effect of oxytetracycline and lead on soil enzymatic activity and microbial biomass. Environ. Toxicol. Pharmacol. 2013, 36, 667-674.

(19) Suleiman, M.; Al-Haj, Qasem.; Hussein, A. Synthesis of zinc oxide and cobalt oxide nanoparticles in surfactant/antibiotics shell and investigating their anti-bacterial activities. An-Najah National University, 2013.

(20) Wu, L.; Pan, X.; Chen, L.; Huang, Y.; Teng, Y.; Luo, Y.; Christie, P. Occurrence and distribution of heavy metals and tetracyclines in agricultural soils after typical land use change in east China. Environ. Sci. Pollut. Res. 2013, 20, 8342-8354.

(21) Ma, T.; Chen, L.; Wu, L.; Christie, P.; Luo, Y. Toxicity of OTC to Ipomoea aquatica Forsk. and to microorganisms in a long-term sewage irrigated farmland soil. Environ. Sci. Pollut. Res. 2016, 23, 15101-15110.

(22) Hund-Rinke, K.; Simon, M.; Lukow, T. Effects of tetracycline on the soil microflora: function, diversity, resistance. J. Soils Sediments 2004, $4,11-16$.

(23) Boonsaner, M.; Hawker, D. W. Accumulation of oxytetracycline and norfloxacin from saline soil by soybeans. Sci. Total Environ. 2010, 408, 1731-1737.

(24) Boonsaner, M.; Hawker, D. W. Investigation of the mechanism of uptake and accumulation of zwitterionic tetracyclines by rice (Oryza sativa L.). Ecotoxicol. Environ. Saf. 2012, 78, 142-147.

(25) Kong, W. D.; Zhu, Y. G.; Liang, Y. C.; Zhang, J.; Smith, F. A.; Yang, M. Uptake of oxytetracycline and its phytotoxicity to alfalfa (Medicago sativa L.). Environ. Pollut. 2007, 147, 187-193.

(26) Ma, Y.; Prasad, M. N. V.; Rajkumar, M.; Freitas, H. Plant growth promoting rhizobacteria and endophytes accelerate phytoremediation of metalliferous soils. Biotechnol. Adv. 2011, 29, 248-258.

(27) Sun, M.; Fu, D.; Teng, Y.; Shen, Y.; Luo, Y.; Li, Z.; Christie, P. In situ phytoremediation of $\mathrm{PAH}$-contaminated soil by intercropping alfalfa (Medicago sativa L.) with tall fescue (Festuca arundinacea Schreb.) and associated soil microbial activity. J. Soils Sediments 2011, 11, 980989.

(28) Ma, T.; Luo, Y.; Christie, P.; Teng, Y.; Liu, W. Removal of phthalic esters from contaminated soil using different cropping systems: A field study. Eur. J. Soil Biol. 2012, 50, 76-82.

(29) Wu, L.-h.; Zhou, S.-b.; Bi, D.; Guo, X.-h.; Qin, W.-h.; Wang, H.; Wang, C.-j; Luo, Y.-m. Sedum plumbizincicola, a new species of the Crassulaceae from Zhejiang. China. Soils (in Chinese) 2006, 38, 632-633.

(30) Wu, L. H.; Liu, Y. J.; Zhou, S. B.; Guo, F. G.; Bi, D.; Guo, X. H.; Baker, A. J. M.; Smith, J. A. C.; Luo, Y. M. Sedum plumbizincicola XH Guo et SB Zhou ex LH Wu (Crassulaceae): A new species from Zhejiang Province, China. Plant Syst. Evol. 2013, 299, 487-498.

(31) Li, Z.; Wu, L.; Hu, P.; Luo, Y.; Christie, P. Copper changes the yield and cadmium/zinc accumulation and cellular distribution in the cadmium/zinc hyperaccumulator Sedum plumbizincicola. J. Hazard. Mater. 2013, 261, 332-341.

(32) Cooperative Research Group on Chinese Soil Taxonomy. Chinese Soil Taxonomy; Science Press: Beijing, New York, 2001; pp 133-167.

(33) Lu, R. K. Analytical methods for soil and agrochemistry; Agricultural Science and Technology Press, Beijing (in Chinese), 2000.

(34) Luo, K.; Ma, T.; Liu, H.; Wu, L.; Ren, J.; Nai, F.; Li, R.; Chen, L.; Luo, Y.; Christie, P. Efficiency of repeated phytoextraction of cadmium and zinc from an agricultural soil contaminated with sewage sludge. Int. J. Phytorem. 2015, 17, 575-582.
(35) McGrath, S. P.; Cunliffe, C. H. A simplified method for the extraction of the metals $\mathrm{Fe}, \mathrm{Zn}, \mathrm{Cu}, \mathrm{Ni}, \mathrm{Cd}, \mathrm{Pb}, \mathrm{Cr}, \mathrm{Co}$, and $\mathrm{Mn}$ from soils and sewage sludges. J. Sci. Food Agric. 1985, 36, 794-798.

(36) Yao, H.; He, Z. L.; Wilson, M. J.; Campbell, C. D. Microbial biomass and community structure in a sequence of soils with increasing fertility and changing land use. Microbial Ecol. 2000, 40, 223-237.

(37) Doi, A. M.; Stoskopf, M. K. The kinetics of oxytetracycline degradation in deionized water under varying temperature, $\mathrm{pH}$, light, substrate, and organic matter. J. Aquat. Anim. Health 2000, 12, 246-253.

(38) Tang, X.; Bernard, L.; Brauman, A.; Daufresne, T.; Deleporte, P.; Desclaux, D.; Souche, G.; Placella, S. A.; Hinsinger, P. Increase in microbial biomass and phosphorus availability in the rhizosphere of intercropped cereal and legumes under field conditions. Soil Biol. Biochem. 2014, 75, 86-93.

(39) Wan, Y.; Bao, Y.; Zhou, Q. Simultaneous adsorption and desorption of cadmium and tetracycline on cinnamon soil. Chemosphere 2010, 80, 807-812.

(40) Chen, L.; Ma, T.; Pan, X.; Li, Z.; Wu, L.; Luo, Y. Sorptiondesorption characters of oxytetracycline and the effects on soil heavy metal desorption behavior in heavy metal-organic pollutants mixed contaminated soils. Acta Pedologica Sinica (in Chinese) 2015, 52, 104111.

(41) Chen, L. Ecological risks and phytoremediation of oxytetracycline in a heavy metals-organic pollutants co-contaminated soil. Master's Thesis (in Chinese), University of Chinese Academy of Sciences, Beijing, 2014.

(42) Gramlich, A.; Tandy, S.; Frossard, E.; Eikenberg, J.; Schulin, R. Availability of zinc and the ligands citrate and histidine to wheat: Does uptake of entire complexes play a role? J. Agric. Food Chem. 2013, 61, 10409-10417.

(43) Bernanke, J.; Köhler, H. R. The impact of environmental chemicals on wildlife vertebrates. Rev. Environ. Contam. Toxicol. 2009, 198, 1-47.

(44) Fridovich, I. Superoxide radical and superoxide dismutases. Annu. Rev. Biochem. 1995, 64, 97-112.

(45) Verma, S.; Dubey, R. S. Lead toxicity induces lipid peroxidation and alters the activities of antioxidant enzymes in growing rice plants. Plant Sci. 2003, 164, 645-655.

(46) Wang, Y.; Wu, S.; Chen, L.; Wu, C.; Yu, R.; Wang, Q.; Zhao, X. Toxicity assessment of 45 pesticides to the epigeic earthworm Eisenia fetida. Chemosphere 2012, 88, 484-491.

(47) Mittal, S.; Kumari, N.; Sharma, V. Differential response of salt stress on Brassica juncea: Photosynthetic performance, pigment, proline, D1, and antioxidant enzymes. Plant Physiol. Biochem. 2012, 54, 17-26.

(48) Zhou, J.; Zhu, X.-s.; Cai, Z. -h. Tributyltin toxicity in abalone (Haliotis diversicolor supertexta) assessed by antioxidant enzyme activity, metabolic response, and histopathology. J. Hazard. Mater. 2010, 183, $428-433$.

(49) Bigorgne, E.; Foucaud, L.; Lapied, E.; Labille, J.; Botta, C.; Sirguey, C.; Falla, J.; Rose, J.; Joner, E. J.; Rodius, F.; Nahmani, J. Ecotoxicological assessment of $\mathrm{TiO}_{2}$ byproducts on the earthworm Eisenia fetida. Environ. Pollut. 2011, 159, 2698-2705. 